\title{
EFEITOS DO ACIDO GIBERÉLICO (GA) E DO CLORETO DE CLOROCOLINA (CCC) SOBRE O CRESCIMENTO INICIAL DE Brachiaria plantaginea (Link) Hitch.
}

\author{
J. G. MACHADO NETO*; R. A. PITELLI**; D. PERECIN** \& P. R. C. CASTRO*** \\ * Auxiliar de Ensino, FEIS/UNESP. Av. Bra sil \\ Centro, 56 - 15.378 - Ilha Solteira - SP. \\ ** Professor Assistente Doutor e Professor \\ Titular, FCAV/UNESP. Rodovia Carlos T o- \\ nanni, km 5 - 14.870 - Jaboticabal - SP. \\ *** Professor Adjunto, Botânica — ES ALQ - \\ USP, 13.400 - Piracicaba - SP. \\ Parte do Trabalho de Graduação apresenta - \\ do na FCAV/UNESP, Jaboticabal. \\ Trabalho apresentado na 33.' Reunião Anual \\ da SBPC, Salvador, 1981.
}

\section{RESUMO}

Com o objetivo de verificar os efeitos do ácido giberélico (GA) e do cloreto de clorocolina (CCC) sobre o crescimento e desenvolvimento inicial de Brachiaria plantaginea, instalou-se a presente pesquisa em local com alta infestação dessa espécie, utilizando-se dos seguintes tratamentos: CCC nas concentrações de 1000 e 2000 ppm, GA na de 50 e 100 ppm e uma testemunha sem aplicação dos fitoreguladores. Na época de aplicação dos produtos as plantas apresentavam, em média, sete folhas e idade em torno de 25 dias. Os parâmetros avaliados foram altura do dossel, altura média das plantas, número médio de perfilhos por planta, biomassa seca da parte aérea total e por indivíduo.

Os resultados foram avaliados 22 dias após a aplicação, quando se verificou que a biomassa total das plantas não foi alterada significativamente pelos tratamentos. Não ocorreram efeitos de doses e nem de interações entre fitoreguladores com dose em quaisquer dos parâmetros avaliados. Não se verificaram efeitos do CCC nos dados obtidos e todas as alterações ocorridas foram devidas à aplicação do GA que aumentou, significativamente, a altura de dossel e dos indivíduos de Brachiaria plantaginea e reduziu o perfilhamento da planta daninha.

Palavras chave: Brachiaria plantaginea, fitoreguladores, giberelina, chlormequat.

\section{SUMMARY}

EFFECTS OF GIBBERELLIC ACID (GA) AND CHLOROCHOLINE CHLORIDE (CCC) ON Brachiaria plantaginea (Link) Hitch. GROWTH
The effects of gibberellic acid (GA) and chlorocholine chloride (CCC) was studied on Brachiaria plantaginea initial growth. An experiment was carried out on a high infestation area in field conditions. The treatments were: $\mathrm{CCC}$ at 1000 and $2000 \mathrm{ppm}, \mathrm{GA}$ at 50 and $100 \mathrm{ppm}$ and check. At the application time, the plants had, in average, 7 leaves and 25 days Of age. Canopy and plant height, tillering and shoot dry matter weight were measured.

The total dry matter weight was not affected by any treatment. Dosig or interaction between dosis and growth substances did not effect any studied parameter. GA increased the canopy and individual plant height and decreased the plant tillering.

Keywords: Brachiaria plantaginea, growth regulators, gibberellin, chlormequat.

\section{INTRODUÇÃO}

Num sistema integrado de manejo de plantas daninhas em áreas agrícolas a utilização de fitoreguladores pode ser de grande importância não só devido as suas interações com os produtos herbicidas, como no relacionamento competitivo cultura-mato. Sabe-se que a eficiência competitiva de uma espécie está relacionada com sua capacidade e velocidade de recrutar os fatores do meio que se tornam limitantes durante $\mathrm{o}$ crescimento $\mathrm{e}$ desenvolvimen to conjunto na comunidade vegetal. Assim, os fitoreguladores po- 
dem alterar as velocidades e intensidades de crescimento de diversas espécies vegetais e com isso, abre-se perspectiva de pesquisa sobre as possibilidades de suas utilizações nesta prática agrícola. Neste contexto, instalou-se o presente trabalho, que objetivou realizar observações preliminare s sobre os efeitos do chlorm equat ( CCC) e do ácido giberélico (GA) sobre o crescimento e desenvolvimento inicial de Brachiaria plantaginea (Link) Hitch., em condições de campo.

Não foi encontrada, na literatura disponível, qualquer referência evidenciando os efeitos destes fitoreguladores sobre a referida planta daninha. No entanto, alguns autores constataram efeitos des tes compostos sobre algu mas gramíneas cultivadas. $\mathrm{O} \mathrm{CCC}$ pode promover redução na altura de plantas de trigo (3, 5 e 8) e aumento no perfilhamento (3). Goodin et al (6) citam efeitos do CCC também reduzindo a altura de plantas de cevada. Em cana-de-açúcar, foi observado efeito do GA aumentando significativamente a altura da planta (2).

\section{MATERIAIS E MÉTODOS}

O presente trabalho foi instalado no município de Jaboticabal, SP, em área com alt a infestação da gramínea, sobre solo Latossol Vermelho Escuro fase arenosa. Quan do as plantas apre sentavam, em média, sete folhas e em torno de 25 dias de idade, locaram-se os blocos experimentais em número de sete, levando-se em consideração o grau de infestação e distribu ição geog ráfica dos indi vídu os. Os tratamentos testad os for am CCC a 1000 e 2000 ppm, GA a 50 e 100 ppm e testemunha sem fitoreguladores. As parcelas experimentais foram de $2,25 \mathrm{~m} 2$, justamente para que se pudesse obter maior uniformidade dentro dos blocos. Como área útil considerou-se $0,3 \mathrm{~m}^{2}$ no centro de cada parcela.

A aplicação dos fitoreguladores foi realizada no dia 06/10/1979 no final da tarde, das $17: 30$ às $18: 40$ hs, com um pulverizador manual, com depósito para 4,01 , equipado com um bico tipo leque 8004, aplicando-se de maneira uniforme sobre as parcelas e vazão de 300 1/ha de solução.

A avaliação do experimento ocorreu no dia 28 '10/1979, 22 dias após as aplicações dos fitoreguladores. Inicialmente avaliou-se a altura do dossel e em seguida as plantas foram removidas manualmente e acondicionadas em sacos plásticos previamente etiquetados. No laboratório, separou-se aleatoriamente 15 plantas por parcela das quais obteve-se o comprimento e o número de perfilhos de cada uma. Reunindo-se às restantes, cortou-se as raízes remanescentes e acondicionou-se em sacos de papel, previamente numerados, levando-se à estufa de circulação forçada de ar, à temperatura de $70-80^{\circ} \mathrm{C}$, para a obtenção do peso da biomassa seca da parte aérea.

Os dados obtidos foram analisados inicialmente segundo os testes F e Tukey, este para comparação de médias, e em seguida realizou-se o desdobramento de graus de liberdade de tratamentos para os contrastes desejados.

\section{RESULTADOS E DISCUSSÃO}

Os resultados e análises estatísticas estão apresentados no quadro 1, onde se observa que a Brachiaria plantaginea respondeu significativamente aos tratamentos a que foi submetida em todos os parâmetros avaliados, exceto para o peso da biomassa seca total da parcela.

Tanto a altura do dossel como a altura média das plantas foram incrementadas pelos produtos. O teste de Tukey não mostrou diferen ças signifi cativas entre a testemunha e os tratamentos com $\mathrm{CCC}$, embora este fitoregulador apresentasse tendências em incrementar o crescimento das plantas no período estudado. Em outras gramíneas esta tendência é justamente ao contrário como pode-se verificar em trigo $(8,5,3)$, e em cevada (6). Para Harada e Lang (7) o CCC deve provocar retardamento no crescimento, pois, parece atuar inibindo a biossíntese de ácido giberélico. Por outro lado, o GA evidencou $\mathrm{O}$ seu efeito de promotor de crescimento, incrementando 
significativamente a altura das plantas, independentemente da concentração e diferindo significativamente dos demais tratamentos, estando de acordo com Anônimo (2) que ainda associa à este fato aumento na área foliar e biomass a da parte aérea.

O perfilhamento das plantas, número médio de perfilhos por planta, foi reduzido bastante pelo GA, efeito este também verificado por Bull, citado por Anônimo (2), em cana-de-açúcar.

$\mathrm{O}$ efeito dos tratamentos sobre a biomassa seca acumulada por planta foi mais intenso com a aplicação do ácido giberélico, quando se verificaram incrementos de $43,8 \%$ e $59,4 \%$ para as concentrações de 50 e 100 ppm, respectivamente. Anônimo (2) já havia citado que o maior crescimento vegetativo de gramíneas em que havia sido aplicado ácido giberélico, era, geralmente, acompanhado de aumento no peso da matéria seca acumulada. Os efeitos do CCC não foram tão pronunciados a ponto de diferirem estatisticamente da testemunha, embora as tendências tivessem sido de $15,6 \%$ e $18,8 \%$ em aumento deste parâmetro nas concentrações de 1000 e 2000 ppm, respectivamente.

Quadro 1 - Dados de altura média do dossel e altura média das plantas, número médio de perfi lhos, peso da biomassa seca da parte aérea por indivíduo e total de Brachiaria plantaginea (Link) Hitch., 22 dias após a aplicação dos fitoreguladores. Média de 7 repetições. Jaboticabal, 1979.

\begin{tabular}{|c|c|c|c|c|c|}
\hline \multirow{2}{*}{ Tratamentos } & \multicolumn{2}{|c|}{ Altura média $(\mathrm{cm})$} & \multirow{2}{*}{$\begin{array}{l}\mathrm{N} \text {. de }^{-} \\
\text {perfilhos }\end{array}$} & \multicolumn{2}{|c|}{ Biomassa Seca (g) } \\
\hline & Dossel & $\mathrm{p} /$ indiv. & & $\mathrm{p} /$ indiv. & Total \\
\hline $\begin{array}{l}\text { Testemunha } \\
\text { CCC } 1000 \mathrm{ppm} \\
\text { CCC } 2000 \mathrm{ppm} \\
\text { GA } 50 \mathrm{ppm} \\
\text { GA } 100 \mathrm{ppm}\end{array}$ & $\begin{array}{l}16,00 \mathrm{a}^{(1)} \\
19,07 \mathrm{a} \\
21,50 \mathrm{a} \\
27,43 \mathrm{~b} \\
27,86 \mathrm{~b}\end{array}$ & $\begin{array}{l}26,01 \mathrm{a} \\
31,00 \mathrm{a} \\
30,64 \mathrm{a} \\
39,03 \mathrm{~b} \\
38,03 \mathrm{~b}\end{array}$ & $\begin{array}{l}3,67 \mathrm{a} \\
3,44 \mathrm{ab} \\
3,43 \mathrm{ab} \\
3,00 \mathrm{~b} \\
3,01 \mathrm{ab}\end{array}$ & $\begin{array}{l}0,32 \mathrm{a} \\
0,37 \mathrm{ab} \\
0,38 \mathrm{ab} \\
0,46 \mathrm{ab} \\
0,51 \mathrm{~b}\end{array}$ & $\begin{array}{r}98,58 \mathbf{a} \\
102,37 \mathbf{a} \\
93,41 \mathbf{a} \\
118,37 \mathbf{a} \\
109,88 \mathbf{a}\end{array}$ \\
\hline $\begin{array}{l}\text { F (blocos) } \\
\text { F (trat.) } \\
\text { C.V. }(\%) \\
\text { D.M.S. }(5 \%)\end{array}$ & $\begin{array}{c}5,84^{\star *} \\
12,54^{\star *} \\
17,34 \\
6,12\end{array}$ & $\begin{array}{l}2,75^{\star} \\
14,97^{* *} \\
12,11 \\
6,25\end{array}$ & $\begin{array}{c}4,59^{* *} \\
3,40^{\star} \\
12,74 \\
0,66\end{array}$ & $\begin{array}{c}0,74 \text { ns } \\
4,11^{*} \\
24,41 \\
0,16\end{array}$ & $\begin{array}{l}3,52^{*} \\
0,90^{\mathrm{ns}} \\
26,12 \\
43,03\end{array}$ \\
\hline $\begin{array}{l}\text { Trat. vs. Test. } \\
\text { Efeito de Fitor. (F) } \\
\text { Efeito de Doses (D) } \\
\text { Interações F x D }\end{array}$ & $\begin{array}{r}23,59^{* *} \\
25,16^{* *} \\
0,95^{\text {ns }} \\
0,46^{\mathrm{ns}}\end{array}$ & $\begin{array}{r}33,22^{* *} \\
26,43^{* *} \\
0,20 \mathrm{~ns} \\
0,05 \mathrm{~ns}\end{array}$ & $\begin{array}{l}6,37^{*} \\
7,23^{\text {** }} \\
4,00-10 \mathrm{~ns} \\
0,01^{\text {ns }}\end{array}$ & $\begin{array}{l}6,15^{\star} \\
0,01^{\mathrm{ns}} \\
0,83^{\mathrm{ns}} \\
0,36^{\mathrm{ns}}\end{array}$ & $\begin{array}{l}0,43 \mathrm{~ns} \\
2,48 \mathrm{~ns} \\
0,71 \mathrm{~ns} \\
5,00-4 \mathrm{~ns}\end{array}$ \\
\hline
\end{tabular}

ns — não significativo

** - significativo a nível de $5 \%$ de probabilidade *

- significativo a nível de $1 \%$ de probabilidade (1)

- médias acompanhadas pela mesma letra não diferem estatisticamente entre si pelo teste de Tukey ao nível de $5 \%$ de probabilidade

A biomassa total acumulada pela planta daninha não foi afetada significativamente pelos tratamentos. $\mathrm{O}$ incremento observado para o peso de plantas individuais, as quais foram tomadas em uma amostra de 15 plantas por parcela, não se manteve quando se considerou a biomassa total. Talvez este fato se deva à amostragem na qual procurou-se colher ind iví duos médios de cada população, sendo bastante difícil decidir-se pelas populações que tivessem maior ou menor porcentagem de indivíduos em cada segmento acima ou abaixo da média.

Pelos resultados observados, o ácido giberélico provocou alterações mais proeminentes na gramínea e, baseando-se de 
que o fato do acúmulo de biomassa seca não ter sido alterado, acredita-se que os fitoreguladores não alteram a competitividade da planta daninha em termos de materiais de constituição como água, dióxido de carb ono e nutrien tes. No entanto, a competitividade por luz é incrementada com a maior altura das plantas.

\section{LITERATURA CITADA}

1. Anônimo. Soybeans, Mississipi Agricultural Experiment Station Annual Report, 1968. p. 11-12.

2. Anônimo. Berelex (gibberellic acid). Londres, Imperial Chemical Industries, s/data. 43 p.

3. Bokhari, U.G. \& Youngner, U.B. Effects of CCC on the growth of wheat plants and their intreated progeny. Agronomy Jour. nal 63: 809-811, 1971.
4. Comissão de Solos. Levantamento de reconhecimento dos solos do Estado de São Paulo e Rio de Janeiro. Rio de Janeiro, CNEPA/SNPA, 1960. 634 p. (Boletim 12).

5. El Damaty, A. H.; Kuhn, H. \& Linser, H Whater relations of wheat plants under the influence of (2-cloroethyl) trimethy. lammonium chloride (CCC). Physiologia Plantarum 13: 650-657, 1965.

6. Goodin, J. R.; Mackell, C. M. \& Webb, F. L Influence of $\mathrm{CCC}$ on water use and growth characteristics of barley. Agronomy Jour. nal 44: 453-454, 1966.

7. Harada, H. \& Lang, A. Effects of some (2-cloroethyl) trimethylammonium chloride analogs and other growth retardants on gibberellin biosynthesis in Fusarium moniliforme. Plant Physiology 40: 176-183, 1965.

8. Tolbert, N.E. (2-chloroethyl) trimethylammonium chloride and related compounds as plant growth substances. II. Effect on growth of wheat. Plant Physiology 35: $380-385,1960$. 